AUTHORS' VERSION

\title{
An assessment of the audibility of sound from human transport by breeding Weddell seals (Leptonychotes weddellii)
}

\author{
Tamara D. van Polanen Petel, John M. Terhune, Mark A. Hindell and Melissa A. Giese
}

\begin{abstract}
Anthropogenic noise generated through travel in the Antarctic has the potential to affect the regions wildlife. Weddell seals (Leptonychotes weddellii) in particular can be exposed to anthropogenic noise because they live under, and breed on, the fast ice on which humans travel. To investigate the potential effects of anthropogenic noise on Weddell seals we developed sound profiles for pedestrian travel, over-snow vehicles, aircraft and watercraft operating at various distances and altitudes from breeding seals. The received 1/3-octave noise levels were then related to an assumed detection threshold for the Weddell seal. We found that most noise levels generated by the pedestrian, quad (4-wheeled, all-terrain vehicle) and Hagglunds (tracked, all-terrain vehicle) were commonly categorised in the inaudible and barely audible range of detection (both in-air and underwater), while noise levels generated by the helicopter, Twin Otter aircraft and Zodiac boat were categorised more commonly in the barely audible and clearly audible range. Experimental underwater recordings of vocal behaviour of Weddell seals exposed to continuous low-amplitude over-snow vehicle noise (i.e. Hagglund operation) were also made. Weddell seals underwater did not alter individual call types in response to low-level Hagglunds noise, but they did decrease their calling rate.
\end{abstract}

\section{Introduction}

Human activity in the Antarctic has been steadily increasing since the continent was discovered in 1820 (Kimball 1999). Early human activities included harvesting of wildlife (pri- marily seals and whales), exploratory expeditions and scien- tific research. In recent decades, activity has been largely limited to science and tourism. Sounds of varying frequen- cies and intensities are associated with most human activities in the region and many activities may affect the wildlife (see, for example, Richardson et al. 1995; National Research Council 2003). Sound is important to marine mammals for foraging and social facilitation, suggesting that alterations of the acoustic medium are potentially adverse for the wildlife.

Despite this, very little research has been conducted to establish whether Antarctic wildlife is affected by anthropogenic noise. Studies have investigated the effect of helicopter operations on the behavioural response of king penguins (Aptenodytes patagonica) (Cooper et al. 1994), emperor penguins (Aptenodytes forsteri) (Giese and Riddle 1999), Adélie penguins (Pygoscelis adeliae) (Culik et al. 1990; Wilson et al. 1991) and southern elephant seals (Mirounga leonina) (Burton and van den Hoff 2002). However, these studies have not differentiated between the acoustic and visual components of the stimuli to which animals were exposed, so it is difficult to draw conclusions about the relative importance of acoustic effects. Studies on marine mammals elsewhere suggest that anthropogenic noise can cause:

(1) changes in behaviour, such as the cessation of feeding and mating, increased alertness, vigilance and agnostic behaviour or increased avoidance and escape behaviour, as suggested by the reactions of harbor seals (Phoca vitu- lina) (Myrberg 1990) and ringed seals (Phoca hispida) (Born et al. 1999),

(2) changes in vocal behaviour, such as the cessation of calls, or changes in call duration, repetition rate, frequency $(\mathrm{kHz})$ and loudness, as evident from responses of beluga whales (Delphinapterus leucas) (Lesage et al. 1999), bottlenose dolphins (Tursiops truncatus) (Scarpaci et al.

2000), Pacific humpbacked dolphins (Sousa chinensis) (van Parijs and Corkeron 2001) and killer whales (Orcinus orca) (Foote et al. 2004),

(3) changes in movement patterns such that animals temporarily or permanently leave an area, as illustrated from studies of harbour seals (Henry and Hammill 2001) and killer whales in Canada (Morton and Symonds 2002),

(4) masking of important sounds, affecting communication, navigation, and predator-prey interactions, as reported for killer whales in Canada (Morton and Symonds 2002),

(5) temporary or permanent hearing loss, or 
(6) physical injury or death (Richardson et al. 1995; National Research Council 2003).

Various measures and conventions designed to control human travel in the vicinity of Antarctic wildlife exist under the Antarctic Treaty System (Kimball 1999). In addition to these, the International Association of Antarctic Tour Operators (IAATO) has developed guidelines for vessel and aircraft operations in the vicinity of wildlife (IAATO 2004). Many of the Antarctic Treaty Nations with research bases in the region, including the Australian Antarctic Division (AAD), have also developed specific operational require- ments for vehicles; however, most of these are not based on scientific studies and have not been tested to determine whether they are actually sufficient to minimise or eliminate noise impacts to wildlife.

The Weddell seal (Leptonychotes weddellii) is the only Antarctic marine mammal that lives under, and breeds on, the same fast ice that people utilise for travel. As a conse- quence, seals near research bases or tourist operations are often exposed to anthropogenic noise. The vocal behaviour of Weddell seals is sophisticated, compared with that of other Antarctic phocids, and they may therefore be especially vul- nerable to acoustic interference (Ray and deCamp 1969; Evans et al. 2004).

Quantifying the effects of noise on the behaviour (and potentially the physical state) of Weddell seals requires knowledge of the auditory threshold of the Weddell seal, the factors affecting the audibility of noises, the sound levels pro- duced by various forms of transport (i.e. their sound profile) and how seals might respond to anthropogenic noise. The aims of this study were to (1) determine audibility by Weddell seals of a number of commonly used Antarctic vehicles and (2) determine, from an experiment of vocal response, whether continuous vehicle noise affected the vocal behaviour of Weddell seals underwater. The spectra of in-air and underwa- ter noises were compared to the assumed detection thresholds for Weddell seals. This enabled us to determine the frequency $(\mathrm{kHz})$ at which there was the greatest amplitude of the noise above the detection threshold. In turn, this process permitted us to estimate detection ranges (in quiet surroundings) of noises independent of their frequency.

\section{Materials and methods}

Study sites, experimental stimuli and experimental design

\section{Sound profiles}

Four recording locations in Princess Elizabeth Land, East Antarctica, were used to record sound profiles: Shirokaya Bay, at $68^{\circ} 31.5 \mathrm{~S}, 78^{\circ} 09 \mathrm{E}$ (Site A), Long Fjord, at $68^{\circ} 30 \mathrm{~S}, 78^{\circ} 20 \mathrm{E}$ (Site B) and Prydz Bay, $10 \mathrm{~km}$ from Davis Station, at $68^{\circ} 33.4 \mathrm{~S}, 78^{\circ} 01 \mathrm{E}$ and $68^{\circ} 35 \mathrm{~S}, 77^{\circ} 51 \mathrm{E}$ (Sites $\mathrm{C}$ and D respectively) (Fig. 1a). These locations were at least $1.75 \mathrm{~km}$ from Weddell seal pupping colonies. Although the sites differed in terms of bathymetry, ice thickness was similar at all sites $\left(\begin{array}{ll}\sim & \mathrm{m}\end{array}\right)$. Recordings were made during November-January 2002/2003 between 0845 and 1445 hours. All recordings were made with low wind and no precipitation.
Stimulus. The modes of transport from which we generated sound profiles were those that are commonly used around Weddell seal colonies. They included a pedestrian wearing crampons (metal spikes worn on the sole of the boot), a quad (4-wheeled, all-terrain vehicle, Honda TRX350), Hagglunds (tracked, all-terrain vehicle, Mercedes Benz BV206D), a helicopter (Aerospatiale AS350B single engine), a Twin Otter aircraft (fixed-wing, fitted with skis), and a Zodiac (5-m inflatable boat with a 35-hp outboard motor).

Sites. Site A was used to record sound profiles from the pedestrian and over-snow vehicles. The ice was polished blue ice with little to no snow cover. We recorded sound profiles from the helicopter from Site B. The ice at this site had a thin $(\sim 1-2 \mathrm{~cm})$ layer of snow in some areas and none in others. Sites $C$ and $D$ were used to record sound profiles for the Twin Otter while Site $D$ was later also used to record the sound from the Zodiac. The ice over which the Twin Otter was flown was covered in a thin layer of snow $(\sim 1-2 \mathrm{~cm})$. Sound profiles from the Zodiac had to be completed later in the season when the ice had largely broken-out.

To guide vehicle movement during recordings, grids were either marked on the ice with canes and marking paint, or on the water with buoys and the use of a GPS (Fig. 2). Distances from the sound record- ing point (SRP) were based on $1 / 2 \log _{10}$ steps, i.e. 1, 31.6, 100, $316 \mathrm{~m}$ and so on, and distances specified by the AAD for travel in the vicinity

of Weddell seals (Fig. 2; AAD 2004a). The distance from the SRP, and therefore the number of transects used, was dependent on the antici- pated amplitude (audible in air to humans) of the sound from a particu- lar mode of transport (Table 1). For experiments involving the pedestrian and the over-snow vehicles, markers were placed on the ice along transects at $10-\mathrm{m}$ and $40-\mathrm{m}$ intervals respectively. To guide the helicopter, markers were placed at $0,100,250$ and $750 \mathrm{~m}$ from the SRP (see 'Recordings'), where the helicopter was directly overhead at $0 \mathrm{~m}$. The Twin Otter made single passes in a straight line directly above the SRP. Speed of travel for the over-snow vehicles and watercraft was based on common speeds used in situ (quad, 15 and $40 \mathrm{~km} \mathrm{~h}^{-1}$; Hagglunds, 15 and $25 \mathrm{~km} \mathrm{~h}^{-1}$; Zodiac, 15 and 35 $\mathrm{km} \mathrm{h}^{-1}$ ), while aircraft speed was based on the cruising speed of the aircraft (helicopter,

$100 \mathrm{~km} \mathrm{~h}^{-1}$; Twin Otter, $220 \mathrm{~km} \mathrm{~h}^{-1}$ ). Distance from the SRP for both the helicopter and the Twin Otter was measured in height (altitude) and horizontal distance.

Sound recordings from each stimulus type were replicated five times. For the pedestrian, quad, Hagglunds and helicopter, sounds were recorded when each stimulus was both approaching and receding from the SRP (Fig. 2). Background noise levels prior to, between the $3 \mathrm{rd}$ and

4th traverse of the vehicle (approximately halfway through the experi- ment) and after the last traverse of the vehicle, were recorded for a period of $15 \mathrm{~min}$ each, giving a total of $45 \mathrm{~min}$ of background noise recordings. The purpose of these recordings was to establish the baseline against which the noise generated by all stimuli tested could be compared (Fig. 3).

Recordings. The SRP was a $15-\mathrm{cm}$-diameter hole drilled through the ice. Two High Tech ${ }^{\mathrm{TM}}$ (HTI-96-Min) hydrophones (Gulfport, Mississippi, USA) with built-in preamplifiers were suspended in the water column, one at $0.5 \mathrm{~m}$ below the ice and the other $1 \mathrm{~m}$ from the bottom if the depth of water was $<30 \mathrm{~m}$, or $29 \mathrm{~m}$ if the depth was $>30 \mathrm{~m}$. Water depth ranged from $6.4 \mathrm{~m}$ to $\sim 250 \mathrm{~m}$. The frequency response of the hydrophones was $\pm 1 \mathrm{~dB}$ from 0.02 to $8 \mathrm{kHz}$ and $\pm 3 \mathrm{~dB}$ from 0.02 to $20 \mathrm{kHz}$. Hydrophone sensitivity was 164.1 and $-163.8 \mathrm{~dB}$ re:

$1 \mathrm{~V} / \mu \mathrm{Pa}$. In-air recordings were made with a Cesva SC- ${ }^{\mathrm{TM}}$ sound-level meter (Barcelona, Spain), which was calibrated with a Cel-282 ${ }^{\mathrm{TM}}$ acoustic calibrator (Kempston, Bedford, UK). The sound-level meter was 'Aweighted' (microphone adjusted to the auditory sensitivity curve of humans). Stereo recordings (underwater) and mono recordings (in-air) were made using a Sony TCD-C100 digital audio tape (DAT) recorder (http://www.sonicstudios.com) $(0.02-20 \mathrm{kHz} \pm 1 \mathrm{~dB}$ at stan- dard recording speed or $0.02-16 \mathrm{kHz} \pm 1 \mathrm{~dB}$ in the long-play mode). The in-air $1 / 3$-octave bands of interest were centred near $1 \mathrm{kHz}$ and thus the 
A-weighting effect of the sound-level meter would not influence the sound measurements. We were therefore able to present sound levels in absolute units of $\mathrm{dB}$ re. $20 \mu \mathrm{Pa}$ at $1 \mathrm{kHz}$, the standard in-air reference level. Underwater, the hydrophones had an essentially flat frequency response over the frequencies of interest and thus the underwater sound levels are presented in absolute units, $\mathrm{dB}$ re. $1 \mu \mathrm{Pa}$, the standard under- water reference level.

\section{Seal detection threshold}

We created an assumed detection threshold (ADT) for Weddell seals, both underwater and in air (Fig. 4), based on experimental studies on harbor seals (Mohl 1968; Terhune 1988, 1991; Kastak and Schusterman 1998; Wolski et al. 2003), harp seals (Pagophilus groen- landicus) (Terhune and Ronald 1971, 1972; and ringed seals Terhune and Ronald 1975). Psychophysically and anatomically, phocids are very similar and little variation has been found in the detection thresholds among several species (Terhune and Turnbull 1995). We therefore took the lowest detection threshold reported for each frequency from the above phocid studies to generate a conservative estimate of in-air and underwater detection thresholds for Weddell seals. Terhune and Turnbull (1995) also found that for a seal to correctly detect a signal

$95 \%$ of the time the sound source had to be $15-20 \mathrm{~dB}$ above its detec- tion threshold. The signal-detection criteria of the harbour seal were found to affect audibility within the 1-20- $\mathrm{dB}$ range, where recognition increased exponentially from 50 to $95 \%$ correct response (Terhune and Turnbull 1995). Another factor that we took into account was that signal levels need to be $\sim 20$ $\mathrm{dB}$ above the threshold to permit recognisable speech in humans (Hirsch 1952).
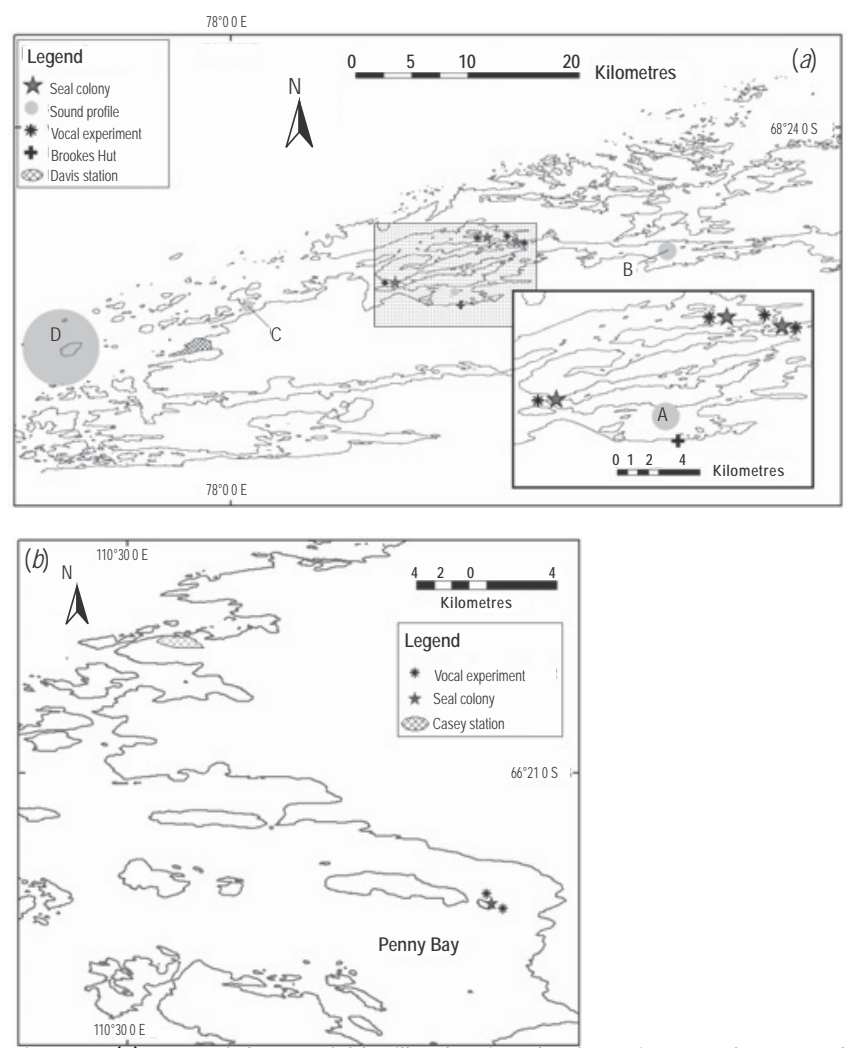

Fig. 1. (a) Map of the Vestfold Hills showing the four sites used to record the sound profiles of the stimuli: the sites used in the vocal response experiment and the location of the seal colonies. (b) Map of Windmill Islands showing the sites used in the vocal response experiment and the location of the seal colony (data from AAD 2004b).
In order to investigate the potential of the noise generated by the stimuli to have an effect on Weddell seals we specified three distinct audibility levels: inaudible; barely audible (noise levels $0-20 \mathrm{~dB}$ above threshold), where the sound would be audible only under low levels of background noise or when the seal is actively listening; and clearly audible, where noise levels were $>20 \mathrm{~dB}$ above threshold.

\section{Vocal response experiment}

To determine whether continuous vehicle noise affected the vocal behaviour of Weddell seals underwater, vocal behaviour was recorded with and without vehicle noise at six Weddell seal breeding colonies in east Antarctica. Two sites were in Penny Bay, Windmill Islands $\left(66^{\circ} 25 \mathrm{~S}\right.$, $110^{\circ} 40 \mathrm{E}$ ) and the remaining four were in Long Fjord, Vestfold Hills $\left(68^{\circ} 35 \mathrm{~S}, 77^{\circ} 58 \mathrm{E}\right)($ Fig. $1 a, b)$. The recordings in the Vestfold Hills (Sites $1-$ 4) were made between 3 and 20 November 2002. The recordings at the Windmill Islands (Sites 5-6) were made between

31 October and 15 November 2001. Although the sites were different in terms of bathymetry, they were similar in terms of ice conditions, i.e.

2-m-thick ice and no surface snow.

At each site, a 50-m-radius circle was drawn around a SRP. This marked the path around which the Hagglund would be operated during experiments. SRPs were situated $300 \mathrm{~m}$ from the centre of the nearest breeding colony to ensure that the closest distance the Hagglunds drove was $250 \mathrm{~m}$ from the nearest breeding seals. This distance met the AAD guideline limit for Hagglunds travel near Weddell seals (AAD 2004a). The circumference of the circle was marked on the ice with spray paint. Two High Tech $^{\mathrm{TM}}$ hydrophones were suspended in the water column through the SRP, one at $0.5 \mathrm{~m}$ below the ice and the other at $27.5 \mathrm{~m}$ or less, but at a minimum of $0.5 \mathrm{~m}$ above the ocean bottom. Stereo record- ings were made as before, using the two hydrophones with built-in preamplifiers and a Sony TCD-C100 DAT

Recordings of Weddell seal vocalisations were made twice at each site during their peak calling times (1800-2000 hours local time for the Windmill Islands and 2000-2200 hours local time for the Vestfold Hills) (Green and Burton 1988). An initial recording of $2 \mathrm{~h}$, on Day 1 of experiments, was made to establish an index of the 'normal' vocal behaviour of the seals in the absence of anthropogenic noise (the control). A second recording, also $2 \mathrm{~h}$ in duration, on Day 2, was made as the Hagglunds operated continuously at a constant speed of $15 \mathrm{~km} \mathrm{~h}^{-1}$ along the marked circle. Therefore, at each recording site ( 6 in total), two $2-h$ recordings were made (one before vehicle activity and one during vehicle activity).

\section{Analysis}

All acoustic signals were calibrated in the field with a Cel-282 acoustic calibrator. The hydrophones were calibrated in the laboratory by the comparison technique using a Bruel \& Kjaer 8100 hydrophone, Bruel \& Kjaer 2635 Charge Preamplifier and Bruel \& Kjaer 4220 pistonphone (Toronto, Ontario, Canada) (comparison technique Caruthers 1977). Recordings were played back with a Sony TCD 750

DAT recorder, a Krohn-Hite Bandpass filter (model 3364) (http://www.krohn-hite.com/index.html) and Digitor C4116 head-phones.

\section{Sound profile}

A 1-s sample of sound was taken from recordings as each stimulus passed each of the marked distances along their respective transects. From this sample, the frequency with the highest amplitude above the assumed detection threshold was selected (both in-air and underwater). We selected an analysing bandwidth that was at, or slightly greater than, a 1/3-octave bandwidth centred at the frequency of interest. We then measured the level $(\mathrm{dB})$ of the 1/3-octave bandwidth using Multispeech (Kay Elemetrics Corp, Model 3700, version 2.2, 1999, Lincoln Park, NJ, USA). Using the $1 / 3$-octave bandwidth distance is a conservative 
approach because the actual masking bandwidth may be smaller (Richardson et al. 1995). A sound profile for each stimulus was then made for the distances tested under the abiotic conditions measured (Tables 2, 3).

Because we took continuous recordings along transects, we were able to determine sound levels at additional distances. However, because of the large number of distances obtained in this method and the close proximity of some of the distances to each other, we chose to present the distances of the transects, i.e. 1, 31.6, $100 \mathrm{~m}$, and additional distances along the furthest transect (Tables 2, 3). The recorded vehicle noise was more than $10 \mathrm{~dB}$ above ambient noise levels when the loudest sounds (those closest to the SRP) were measured, but where the levels were very low (close to being inaudible: Table 3,4 ), the signal to noise ratio in the $1 / 3$-octave bands may not have always been $>10 \mathrm{~dB}$ above the ambient noise levels (Fig. 3) and thus comprised the source plus background noise. The resulting samples of noise spectra were at close range and were subject to change with different distances, abiotic con- ditions (such as wind, ice and snow), and the noises generated by the seals themselves.

\section{Vocal response experiment}

For each 2-h underwater recording, the first 100 clearly discernable calls were sampled. Seal vocalisations were analysed using

(a) Pedestrian grid

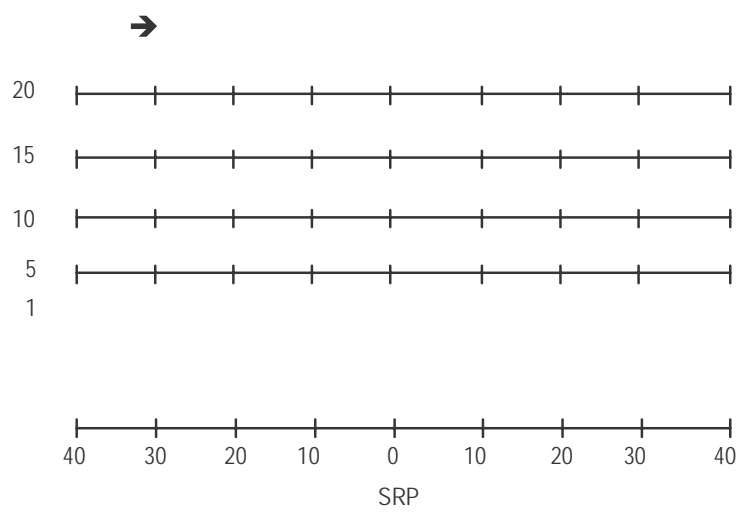

(b) Helicopter grid

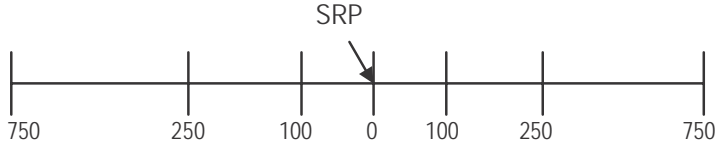

(c) Zodiac grid

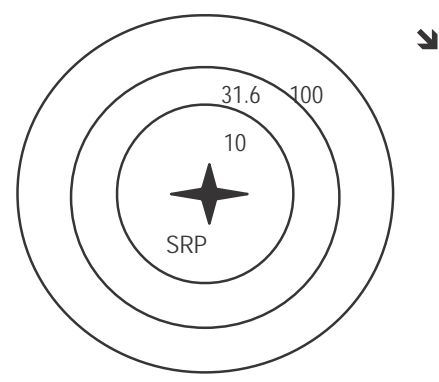

Fig. 2. Grid pattern for the (a) pedestrian, (b) helicopter and (c) Zodiac recordings (the over-snow vehicles grid is similar to the pedestrian grid). Direction of travel is indicated by the arrow. SRP, Sound Recording Point.
Spectrogram (R.S Horne's Spectrogram, version 6.0.9, http://www.visualizationsoftware.com/gram.html) at a sampling rate of

32 or $44 \mathrm{kHz}$ with 16-bit resolution. Only calls between 0.010 and $16 \mathrm{kHz}$ were analysed because of the upper frequency limit $(16 \mathrm{kHz})$ of the DAT recorder in long-play mode. This frequency range is less than that recorded for Weddell seal vocalisations (up to $20 \mathrm{kHz}$ ) (Thomas and Kuechle 1982); however, it allowed us to capture most calls.

Vocalisations were categorised as per Thomas and Kuechle (1982) and Pahl et al. (1997) with the addition of one call type: the tongue click, which we included as a new category (Table 4). For each record- ing the following parameters were quantified: (1) call type (for each of the first 100 calls); (2) call duration; (3) number of elements within each call; (4) whether the focal call was overlapped, i.e. one call occur- ring at the same time as another from a different individual; (5) the time taken to record 100 calls; and (6) the number of calls made in $10 \mathrm{~min}$.

\section{Statistical procedure}

Regression analysis indicated a positive relationship between call dura- tion and the number of elements within a call $\left(R^{2}=0.539, P<0.001\right)$, so call duration alone was used for further analysis. Call duration allowed us to include all call types in the analysis rather than splitting the call types into single and multiple element calls.

Weddell seals may increase the duration of their call in response to another seal calling simultaneously, thus overlapping the calls (Terhune et al. 1994). We therefore examined the effect of overlap on call duration with treatment and site as independent variables in a 2-way analysis of variance (ANOVA). We found that overlap increased in the presence of vehicle noise ( $F$ $=143.61$, d.f. $=1, P<0.001$ ), and therefore the data were separated into overlapped calls and non-overlapped calls. Paired $t$ - tests were then used to compare mean duration of calls between the control and experimental recordings for the five recording sites.

An analysis of similarity (ANOSIM) was used to compare the number of calls (within each call type) with the absence or presence of vehicle noise. We used a $\log (x+1)$ transformation and each site was regarded as a replicate, giving a total sample size of six sites.

Paired $t$-tests were also used to compare the mean length of time required to record 100 calls, as an index of calling rate, and to compare the frequency of occurrence of calls emitted during the 10-min seg- ments of the control and experimental recordings.

Site 1 was excluded from the analyses for comparisons of the time taken to record 100 calls, the number of calls emitted in 10 min and the duration of calls, due to the small number of measurable calls in both the control and experimental recording (9 and 21 respectively).

All data used in $t$-tests were tested for normality and homogeneity of variance, and log-transformations were applied where necessary. The level of all tests was set at 0.05 . Statistical analyses were performed using SPSS (SPSS for windows, version 11.5.1, 1989-2002) and Primer 5 (Plymouth Marine Laboratory, version 5.2, 2001).

\section{Results}

\section{Sound profiles in relation to the assumed detection threshold of the Weddell seal}

Tables 2 and 3 list the 1/3-octave sound level for each of the stimuli and the likely detectability of the sound for a Weddell seal in water and in-air.

The direction of travel, i.e. whether the stimulus was approaching the SRP or receding from it, for the pedestrian, quad, Hagglunds and helicopter, was found to produce slight differences in sound level (mean of $2.7 \mathrm{~dB}$ ); however, this degree of difference was close to the error range of the equip- ment and was therefore disregarded. 


\section{Pedestrian}

The peak frequency (centre of the 1/3-octave band) of underwater noise produced by a person wearing crampons walking on the ice was $1.03 \mathrm{kHz}$. Based on the assumed detection threshold, this frequency would be barely audible to Weddell seals when decibels levels are $>66 \mathrm{~dB}$ re. $1 \mu \mathrm{Pa}$. The noise level generated by the pedestrian walking on the ice at all distances (up to $50 \mathrm{~m}$ ) would be barely audible to a seal under the water (Table 2). The highest noise level recorded (16 dB above threshold) was $25 \mathrm{~m}$ from the SRP, recorded from the lower hydrophone (Fig. 5). No in-air recordings were made.

\section{Over-snow vehicles}

Quad. The peak frequency produced underwater by a quad travelling on sea-ice was within the 1/3-octave band centred at $0.2 \mathrm{kHz}$. The noise would become audible to a Weddell seal at levels above $84 \mathrm{~dB}$ re. $1 \mu \mathrm{Pa}$. In-air, the peak frequency of the quad was $0.86 \mathrm{kHz}$, and from behavioural response experiments (van Polanen Petel, unpublished data) it seems that the seals react to noise levels above $19 \mathrm{~dB}$ re. $20 \mu \mathrm{Pa}$.

The noise produced by a quad at the distances tested would be barely audible to the seal in-air and underwater (Tables 2, 3). The only distance at which the noise would be clearly audible (34 dB above threshold) would be at $1 \mathrm{~m}$, and then at the shallow depth only. Deeper in the water column, the noise would be barely audible. A quad travelling at a dis- tance of $40 \mathrm{~m}$ from the SRP would be barely audible, while a further $10 \mathrm{~m}$ away the quad would be inaudible (Fig. 5). The increases in speed we tested resulted in an increase of $1-5 \mathrm{~dB}$ in the sound level recorded (Table 2, Fig. 5). At $128 \mathrm{~m}$, the underwater sound level of the quad would be $4 \mathrm{~dB}$ above threshold at the shallow depth, and $1 \mathrm{~dB}$ above threshold at $156 \mathrm{~m}$ for the greater depth. At any distance past this point, the quad was determined to be inaudible to Weddell seals (Fig. 5).

Hagglunds. The peak 1/3-octave band of noise produced underwater by Hagglunds travelling on sea-ice was centred at $0.075 \mathrm{kHz}$. This noise would be detected by Weddell seals when levels are $>66 \mathrm{~dB}$ re. $1 \mu \mathrm{Pa}$. In-air, the peak frequency of the Hagglunds was centred at $0.86 \mathrm{kHz}$ and would be audible to seals at levels above $19 \mathrm{~dB}$ re. $20 \mu \mathrm{Pa}$.

The noise produced by Hagglunds at the distances tested would be barely audible to a seal on the ice (Table 3). Observations on the behavioural response of lactating Weddell seals hauled out on the ice to the drive-by of Hagglunds at $400 \mathrm{~m}\left(15 \mathrm{~km} \mathrm{~h}^{1}\right)$ also suggest that the seals cannot hear the vehicle (van Polanen Petel, unpublished data).

Underwater, the loudest noise level from a Hagglunds we recorded (42 $\mathrm{dB}$ above threshold) was made when the vehicle was $1 \mathrm{~m}$ from the SRP (0.5 m below the ice) (Table 2, Fig. 5). This would be the only distance at which the Hagglunds would be clearly audible at the shallow depth, while at the greater depth it would be clearly audible at dis- tances up to 31.6 $\mathrm{m}$. The noise level at both depths decreased to within the 0-19-dB range at $156 \mathrm{~m}$ from the SRP (barely audible), where it would be undetectable between 156 and

$316 \mathrm{~m}$ (Fig. 5). The increase in vehicle speed we tested at the 316-m transect did not influence the audibility of the noise; however, it did increase the sound level by $3-5 \mathrm{~dB}$ at the shallow depth and 0-2 $\mathrm{dB}$ at the greater depth (Table 2, Fig. 5). In comparison to the quad, the underwater noise level from the Hagglunds was louder and was predicted to be audible at greater distances (Fig. 5).

Table 1. Dimensions of the grid used for each of the stimuli together with the distance from location of the Sound Recording Point and the speed of travel

\begin{tabular}{|c|c|c|c|c|c|}
\hline Stimulus & Transect length $(\mathrm{m})$ & Speed $\left(\mathrm{km} \mathrm{h}^{-1}\right)$ & Location of SRP & No. of transects & Distance from SRP \\
\hline Pedestrian & 80 & $3-4$ & Underwater & 8 & $1,5,10,15,20,30,40,50 \mathrm{~m}$ \\
\hline \multirow[t]{4}{*}{ Quad } & 240 & 15 & In-air & 3 & $50,150,250 \mathrm{~m}$ \\
\hline & & & Underwater & 4 & $1,31.6,100,316 \mathrm{~m}$ \\
\hline & & 40 & In-air & 1 & $150 \mathrm{~m}$ \\
\hline & & & Underwater & 2 & $100,316 \mathrm{~m}$ \\
\hline \multirow[t]{4}{*}{ Hagglunds } & 240 & 15 & In-air & 3 & $100,250,400 \mathrm{~m}$ \\
\hline & & & Underwater & 5 & $1,31.6,100,316,486 \mathrm{~m}$ \\
\hline & & 25 & In-air & 1 & $250 \mathrm{~m}$ \\
\hline & & & Underwater & 2 & $316,486 \mathrm{~m}$ \\
\hline \multirow[t]{2}{*}{ Helicopter } & 1600 & 100 & In-air \& underwater & 3 & $\begin{array}{l}200,800,2500 \mathrm{ft} \text { (altitude) } \\
0,100,250,750 \mathrm{~m} \text { (horizontal) }\end{array}$ \\
\hline & & Idle/land/take off & In-air \& underwater & n.a. & $10,100,250,750 \mathrm{~m}$ \\
\hline \multirow[t]{2}{*}{ Twin Otter } & NA & 220 & In-air \& underwater & 5 & $328,500,1500,3000,5000 \mathrm{ft}$ \\
\hline & & Idle/land/take off & In-air \& underwater & n.a. & $20,100,500 \mathrm{~m}$ \\
\hline \multirow[t]{2}{*}{ Zodiac } & No set length & 15 & In-air \& underwater & 11 & $\begin{array}{l}0,10,31.6,100,316,500,1000 \\
1500,2000,2500,3000 \mathrm{~m}\end{array}$ \\
\hline & & 35 & In-air \& underwater & 10 & $\begin{array}{l}\text { 0,31.6,100,316,500,1000, } \\
1500,2000,2500,3000 \mathrm{~m}\end{array}$ \\
\hline
\end{tabular}




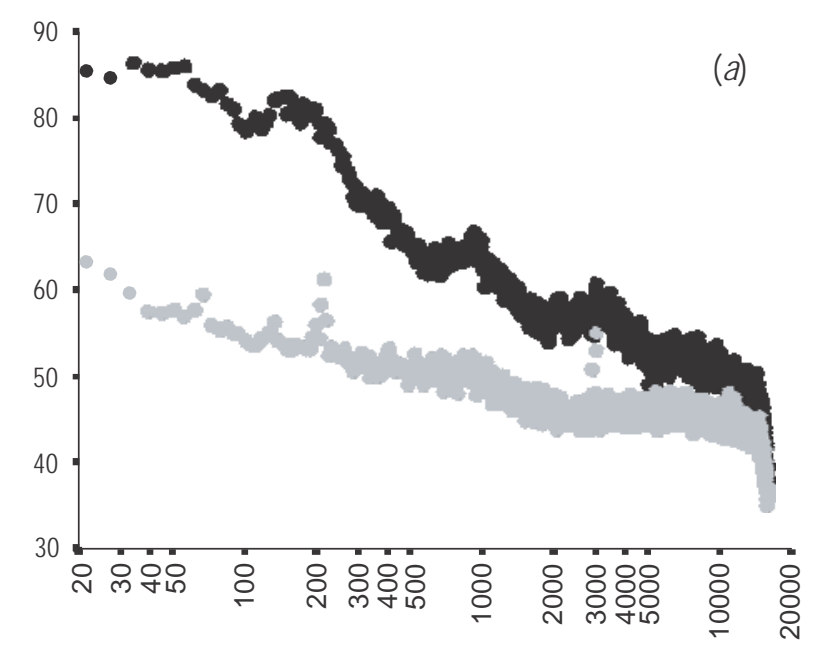

Fig. 3. Examples of the spectra of vehicle noise (black) and ambient noise (grey) underwater for the (a) pedestrian, (b) quad, (d) Hagglunds, ( $f$ ) helicopter, $(h)$ Twin Otter and (j) Zodiac, and in- air for the (c) quad (e) Hagglunds, (g) helicopter, (i) Twin Otter and (k) Zodiac. The vehicle noises were selected from the loudest and closest samples available and the ambient noises were selected from particularly quiet periods. The noises have been influenced by the transmission of the sounds through the air-ice and water-ice interfaces and would change as the ambient noise levels changed or the distance between the noise source and the recording point changed.
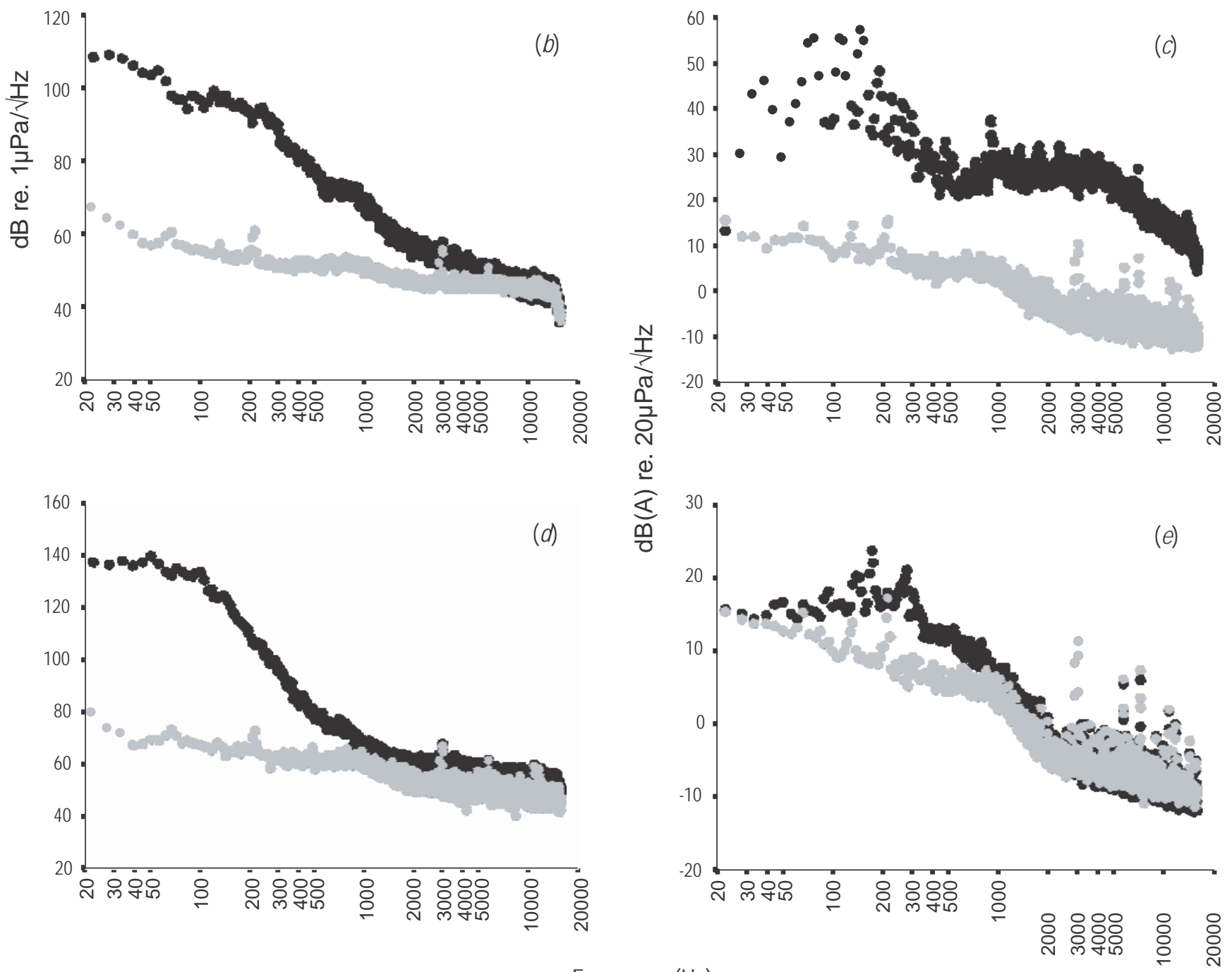

Frequency $(\mathrm{Hz})$ 

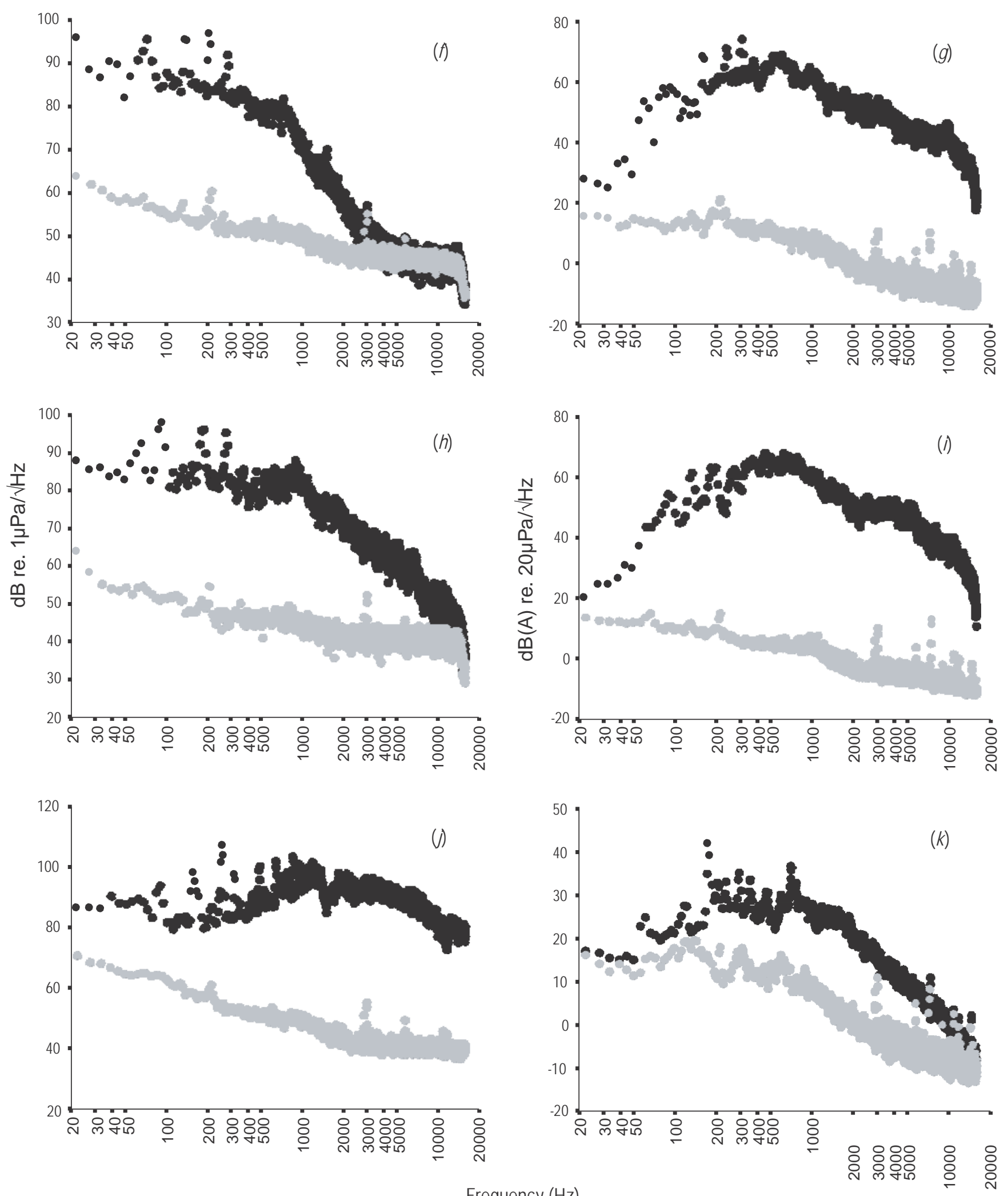

Frequency $(\mathrm{Hz})$ 
Helicopter. The peak 1/3-octave band of the helicopter was centred at $1.03 \mathrm{kHz}$ underwater, and $0.86 \mathrm{kHz}$ in-air. Both frequencies would be detected by a Weddell seal when noise levels are $>66 \mathrm{~dB}$ re. $1 \mu \mathrm{Pa}$ and $19 \mathrm{~dB}$ re. $20 \mu \mathrm{Pa}$ respectively.

At most of the distances tested, the noise of a helicopter idling, landing or during takeoff would be barely audible to a Weddell seal underwater. The only exception occurred during landings at a distance of $10 \mathrm{~m}$ from the SRP, when the noise would be clearly audible (Table 2, Fig. 6). The loudest noise level we recorded occurred during the landing at $10 \mathrm{~m}$ (33 dB above threshold, underwater at the deep hydrophone, and $60 \mathrm{~dB}$ above threshold in-air) (Tables 2, 3). Detectability would be similar in-air for the distances and activities tested with the exception of landing at a distance of $100 \mathrm{~m}$ from the SRP, and takeoff at $250 \mathrm{~m}$, which would be clearly audible (Fig. 7).

During flight, the noise produced by the helicopter at all of the altitudes and distances tested, i.e. up to $800 \mathrm{ft}$ and

$750 \mathrm{~m}$ from the SRP, would be barely audible underwater (Table 2, Fig. 8). Noise level in-air would be clearly audible at altitudes of $2500 \mathrm{ft}$ with distances up to $250 \mathrm{~m}$ from the SRP (Table 3, Fig. 9).

Twin Otter. The peak 1/3-octave band of a Twin Otter was centred at $1.03 \mathrm{kHz}$ underwater and $0.86 \mathrm{kHz}$ in-air. Both frequencies would be audible to the seals at levels

$>66 \mathrm{~dB}$ re. $1 \mu \mathrm{Pa}$ and $19 \mathrm{~dB}$ re. $20 \mu \mathrm{Pa}$ respectively.

The noise from the Twin Otter while idling on the ice would be clearly audible underwater at both depths at a dis- tance of 1 $\mathrm{m}$ (Table 2). Landing at $100 \mathrm{~m}$ would also be clearly audible at both depths, and was the activity that pro- duced the highest noise levels of all stimuli tested during our study (52 dB above threshold). The noise produced during take off at $500 \mathrm{~m}$ would be barely audible to Weddell seals (Fig. 6). The same pattern was observed for in-air recordings

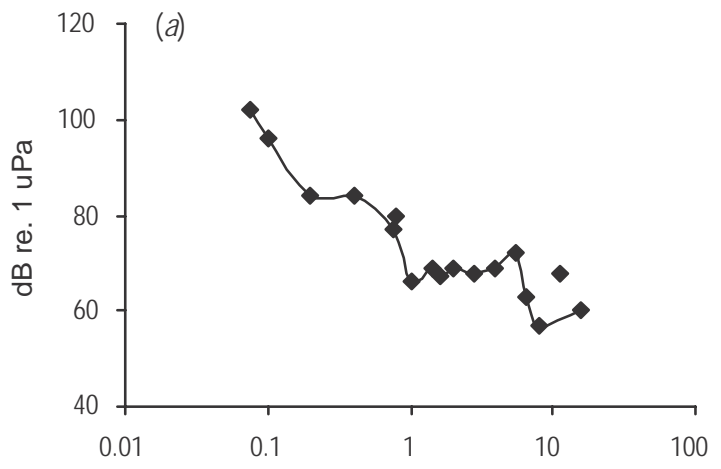

(Table 3, Fig. 7). The loudest in-air recording we measured (62 $\mathrm{dB}$ above threshold) occurred during landing at a dis- tance of $20 \mathrm{~m}$ from the SRP.

During flight, the noise level underwater at all altitudes (330$5000 \mathrm{ft}$ ) would be barely audible. The only distance at which the noise level would be clearly audible was at $500 \mathrm{ft}$ (Fig. 8). Noise recorded in-air would be clearly audible at altitudes up to $3000 \mathrm{ft}$ (Fig. 9).

Zodiac. The peak 1/3-octave band of noise produced by the Zodiac was centred at $1.03 \mathrm{kHz}$ underwater and $0.86 \mathrm{kHz}$ in-air. Both frequencies would be audible to the seals at levels $>66$ $\mathrm{dB}$ re. $1 \mu \mathrm{Pa}$ and $19 \mathrm{~dB}$ re. $20 \mu \mathrm{Pa}$ respectively.

At the distances tested, the Zodiac idling would be clearly audible both underwater and in-air, with the exception of the in-air noise level during idle at $10 \mathrm{~m}$ from the SRP, which would be barely audible (Tables 2, 3, Figs 10, 11). During travel, underwater noise levels would be clearly audible with the exception of travel at $15 \mathrm{~km} \mathrm{~h}^{-1}$ at $1000 \mathrm{~m}$, in which case the noise would be barely audible, and during travel at $35 \mathrm{~km} \mathrm{~h}^{-1}$ at $3000 \mathrm{~m}$ (both depths) (Table 2, Fig. 10). Noise levels in-air would be barely audible when distances exceed $100 \mathrm{~m}$ (up to $2000 \mathrm{~m}$ ) for travel at 15 and $35 \mathrm{~km} \mathrm{~h}^{-1}$ (Fig. 11). The highest decibel level recorded occurred during travel at $35 \mathrm{~km} \mathrm{~h}^{-1}$ directly above the hydrophones and was evident from both underwater (61 dB above threshold) and in-air (35 dB above threshold) recordings. The increase in speed resulted in an average $7 \mathrm{~dB}$ increase in noise level underwater.

\section{Vocal-response experiment}

\section{Call profiles}

There was no significant difference in the pattern of call types used and the number of calls within each call type, between periods when the vehicle was absent and when it was present (global $R=0.048, P=0.234$ ).

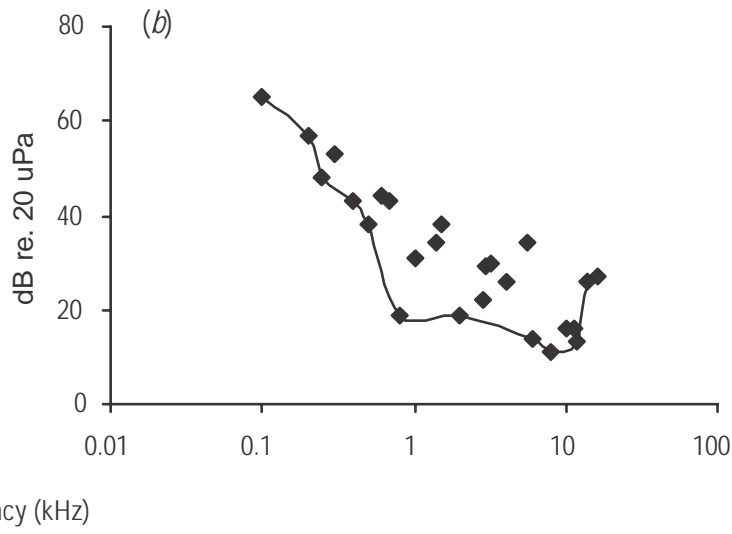

Fig. 4. Assumed Weddell seal audiogram (a) underwater and (b) in-air. Points above the curve illustrate the scatter of the data. The curve represents the lowest threshold measurement at that frequency for any phocid (Mohl 1968; Terhune and Ronald 1971, Terhune and Ronald 1972, Terhune and Ronald 1975; Terhune 1988, Terhune 1991; Kastak and Schusterman 1998; Wolski et al. 2003) 
Table 2. Average sound level (1/3-octave bandwidth, $\mathrm{dB}$ re. $1 \mu \mathrm{Pa}$ ) recorded underwater at a shallow and deep depth of various sources of anthropogenic noise travelling at various speeds and distances from the sound recording point

The sounds are categorised as to their audibility to a theoretical Weddell seal, where inaudible sounds are below threshold, barely audible sounds are $0-20 \mathrm{~dB}$ above threshold and clearly audible sounds are $>20 \mathrm{~dB}$ above threshold

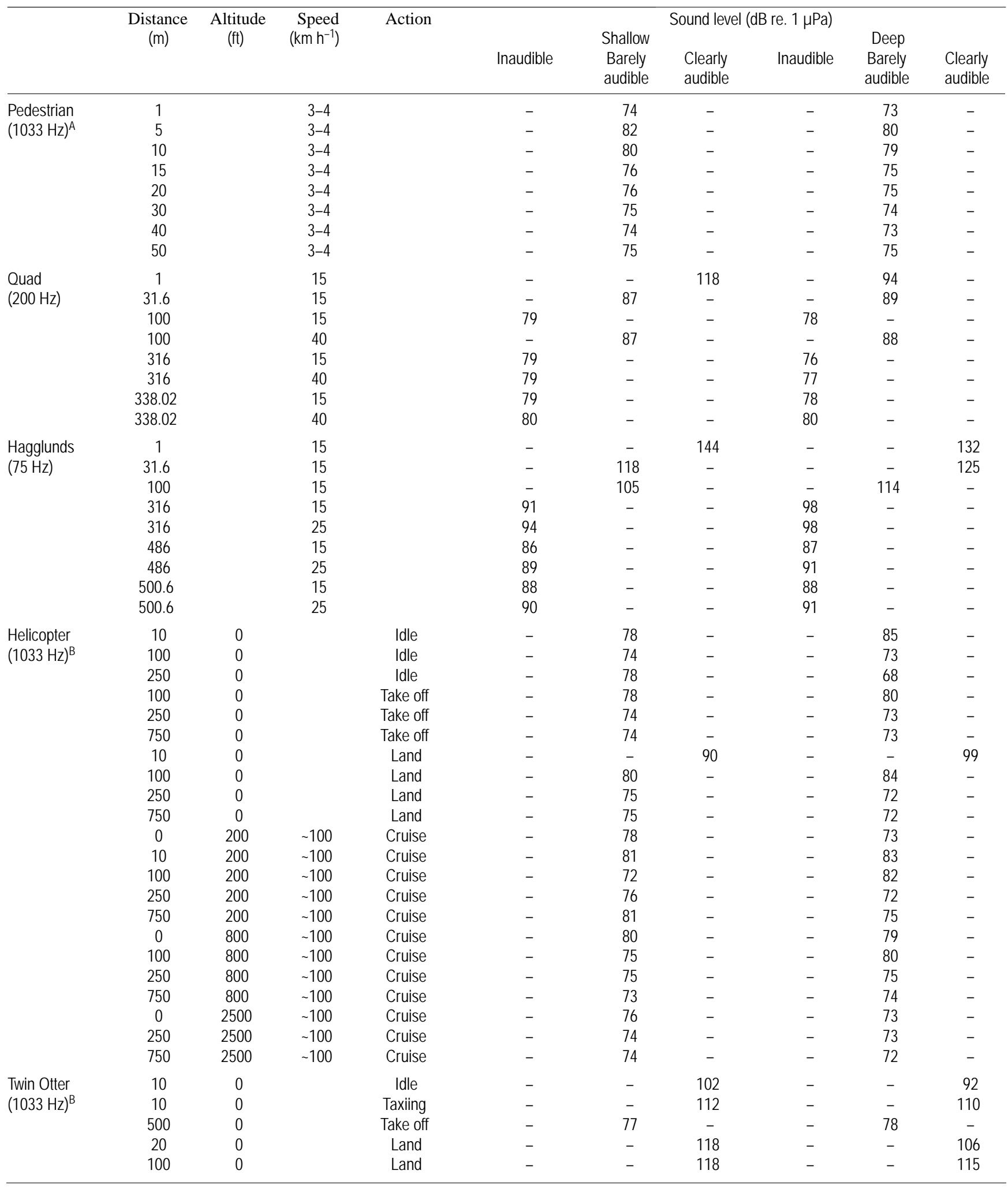


Table 2. (Continued)

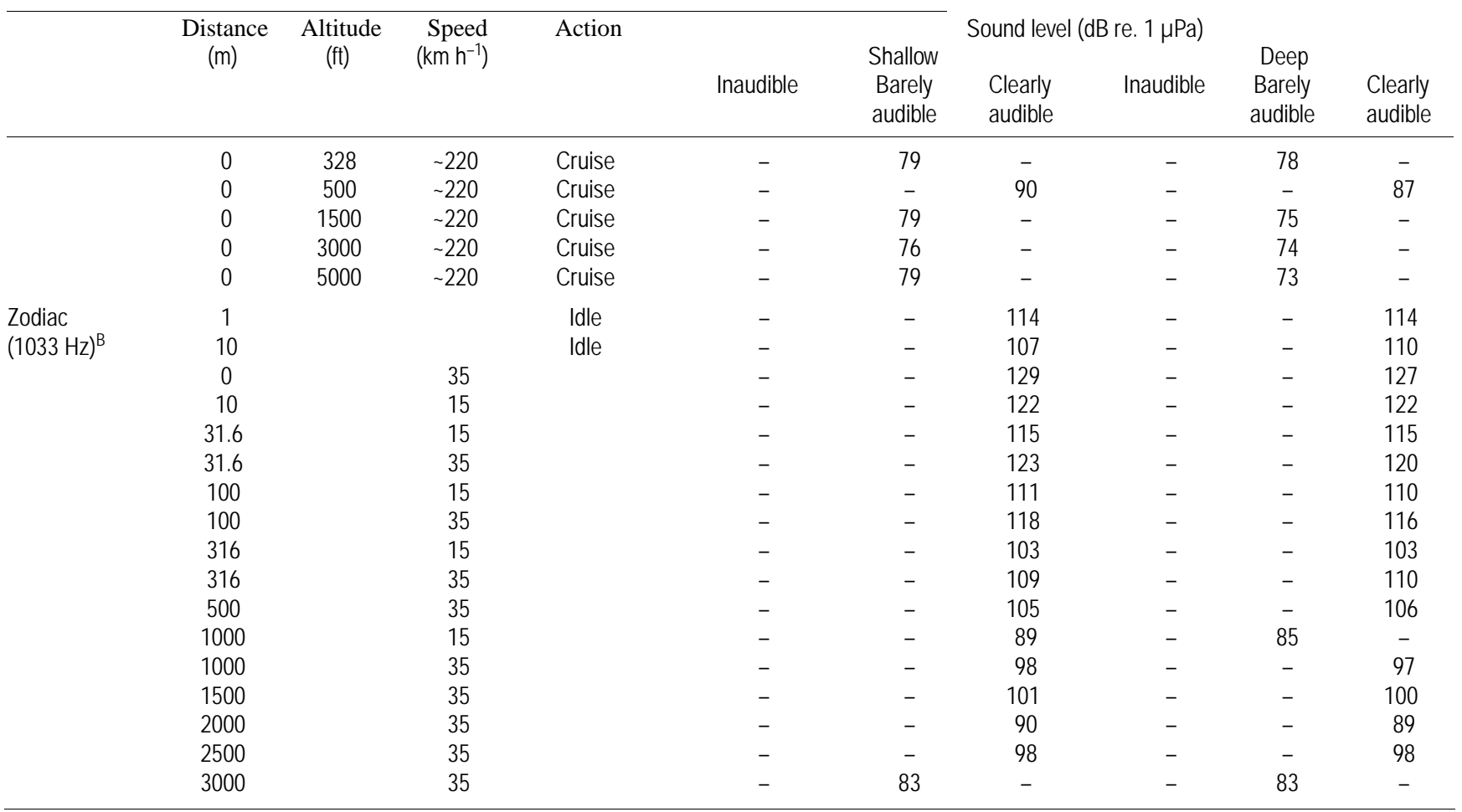

AThe speed of walking was not measured, however a 'normal' walking pace of $3-4 \mathrm{~km} \mathrm{~h}^{-1}$ was maintained.

${ }^{B}$ The centre frequencies of the 1/3-octave bandwidth with the highest amplitude are the same for the pedestrian, aircraft and zodiac, even though these modes of transport are highly different and sound different, because the noise spectrum is relatively flat and the sensitivity of the seal drops as the frequency increases from above $0.8 \mathrm{kHz}$.

\section{Time taken to record 100 calls and the number of calls} in a 10-min period

The time taken to measure 100 clearly discernable calls increased during vehicle activity $(t=3.463$, d.f. $=4$, $P=0.026)$. The frequency of occurrence of calls also decreased during vehicle activity $(t=3.476$, d.f. $=4$, $P=0.025)$.

\section{Call attributes}

Regression analysis indicated that call duration was still positively related to the number of elements in both circumstances (overlap: $R^{2}=0.326, P<0.001$; non-overlap: $R^{2}=$ $0.419, P<0.001)$. Calls that were not overlapped were $4.4 \pm$ 0.80 and $5.4 \pm 0.70 \mathrm{~s}$ long in the control and test situation, respectively, while those that were overlapped were $10.2 \pm$ 0.70 and $10.6 \pm 0.78 \mathrm{~s}$ long during the control and test periods, respectively.

Paired $t$-tests investigating the difference in call duration between the control recording (absence of noise) and the experimental recording (Hagglunds noise) found that contin- uous noise did not influence the duration of calls: overlap

$(t=0.308$, d.f. $=4, P=0.774)$, non-overlap $(t=0.760$, d.f. $=4$, $P=0.442)$.

\section{Discussion \\ Sound profiles in relation to the assumed detection threshold of the Weddell seal}

The sound profiles from this study provide baseline data for several common sources of anthropogenic noise in the Antarctic environment. The peak frequency range relative to the likely detection thresholds of the seals for these modes of transport, underwater and in-air, fell between 0.075 and

$1.03 \mathrm{kHz}$. Weddell seal vocalisations have been recorded at frequencies of $0.2-12.8 \mathrm{kHz}$ by others, with some vocalisa- tions at frequencies as high as $30 \mathrm{kHz}$ (Schevill and Watkins

1971). Thus, in terms of frequency, all of the sources of anthropogenic noise we tested, if generated at sufficient noise levels, would be audible to Weddell seals. Conse- quently, there is a real potential for anthropogenic noise to interfere with seal vocal behaviour and to cause disturbance.

Most of the noise levels recorded in this study, both in-air and underwater/under ice, exceeded background noise levels and were above the assumed detection threshold (ADT) of the Weddell seal at close range. In most cases, anthropogenic noise from nearby sources was $0-20 \mathrm{~dB}$ above the ADT and therefore audibility would be dependent on background noise levels and the behavioural state of an attentive seal. 
Table 3. Average sound level (1/3-octave bandwidth, $\mathrm{dB}$ re. $20 \mu \mathrm{Pa})$ recorded in-air for various sources of anthropogenic noise travelling at various speeds and distances from the sound recording point

Frequency $=861 \mathrm{~Hz}$. The sounds are categorised according to their audibility to a theoretical Weddell seal, where inaudible sounds are below threshold, barely audible sounds are $0-20 \mathrm{~dB}$ above threshold and clearly audible sounds are $>20 \mathrm{~dB}$ above

threshold

\begin{tabular}{|c|c|c|c|c|c|c|c|}
\hline & \multirow[t]{2}{*}{ Distance (m) } & \multirow[t]{2}{*}{ Height (ft) } & \multirow[t]{2}{*}{ Speed $\left(\mathrm{km} \mathrm{h}^{-1}\right)$} & \multirow[t]{2}{*}{ Action } & \multicolumn{3}{|c|}{ Sound level (dB re. $20 \mu \mathrm{Pa})$} \\
\hline & & & & & Inaudible & Barely audible & Clearly audible \\
\hline \multirow[t]{4}{*}{ Quad } & 50 & & 15 & & - & 21 & - \\
\hline & 150 & & 15 & & - & 21 & - \\
\hline & 150 & & 40 & & - & 22 & - \\
\hline & 250 & & 15 & & - & 19 & - \\
\hline \multirow[t]{4}{*}{ Hagglunds } & 100 & & 15 & & - & 23 & - \\
\hline & 250 & & 15 & & - & 24 & - \\
\hline & 250 & & 25 & & - & 21 & - \\
\hline & 400 & & 15 & & - & 22 & - \\
\hline \multirow[t]{22}{*}{ Helicopter } & 10 & & & Idle & - & - & 73 \\
\hline & 100 & & & Idle & - & 39 & - \\
\hline & 250 & & & Idle & - & 34 & - \\
\hline & 100 & & & Take off & - & - & 59 \\
\hline & 250 & & & Take off & - & - & 41 \\
\hline & 750 & & & Take off & - & 36 & - \\
\hline & 10 & & & Land & - & - & 86 \\
\hline & 100 & & & Land & - & - & 51 \\
\hline & 250 & & & Land & - & 37 & - \\
\hline & 750 & & & Land & - & 38 & - \\
\hline & 0 & 200 & $\sim 100$ & Cruise & - & - & 75 \\
\hline & 10 & 200 & $\sim 100$ & Cruise & - & - & 78 \\
\hline & 100 & 200 & $\sim 100$ & Cruise & - & - & 63 \\
\hline & 250 & 200 & $\sim 100$ & Cruise & - & - & 51 \\
\hline & 750 & 200 & $\sim 100$ & Cruise & - & 39 & - \\
\hline & 0 & 800 & $\sim 100$ & Cruise & - & - & 61 \\
\hline & 100 & 800 & $\sim 100$ & Cruise & - & - & 58 \\
\hline & 250 & 800 & $\sim 100$ & Cruise & - & - & 47 \\
\hline & 750 & 800 & $\sim 100$ & Cruise & - & 39 & - \\
\hline & 0 & 2500 & $\sim 100$ & Cruise & - & - & 50 \\
\hline & 250 & 2500 & $\sim 100$ & Cruise & - & - & 43 \\
\hline & 750 & 2500 & $\sim 100$ & Cruise & - & 38 & - \\
\hline \multirow[t]{10}{*}{ Twin Otter } & 10 & & & Idle & - & - & 79 \\
\hline & 10 & & & Taxiing & - & - & 54 \\
\hline & 500 & & & Take off & - & 25 & - \\
\hline & 20 & & & Land & - & - & 88 \\
\hline & 100 & & & Land & - & - & 59 \\
\hline & 0 & 100 & $\sim 220$ & Cruise & - & - & 68 \\
\hline & 0 & 500 & $\sim 220$ & Cruise & - & - & 58 \\
\hline & 0 & 1500 & $\sim 220$ & Cruise & - & - & 45 \\
\hline & 0 & 3000 & $\sim 220$ & Cruise & - & - & 50 \\
\hline & 0 & 5000 & $\sim 220$ & Cruise & - & 38 & - \\
\hline \multirow[t]{13}{*}{ Zodiac } & 1 & & & Idle & - & - & 42 \\
\hline & 10 & & & Idle & - & 38 & - \\
\hline & 0 & & 35 & & - & - & 61 \\
\hline & 10 & & 15 & & - & - & 52 \\
\hline & 31.6 & & 15 & & - & - & 43 \\
\hline & 31.6 & & 35 & & - & & 50 \\
\hline & 100 & & 15 & & - & 34 & - \\
\hline & 100 & & 35 & & - & 36 & - \\
\hline & 316 & & 15 & & - & 28 & - \\
\hline & 316 & & 35 & & - & 33 & - \\
\hline & 1000 & & 15 & & - & 24 & - \\
\hline & 1000 & & 35 & & - & 22 & - \\
\hline & 2000 & & 35 & & - & 24 & - \\
\hline
\end{tabular}


There were only a small number of instances where the noise level was in the clearly audible range ( $>20 \mathrm{~dB}$ above thresh- old). However, these levels were well below the highest level recorded for Weddell seal vocalisations, i.e. $193 \mathrm{~dB}$ re. $1 \mu \mathrm{Pa}$ at $1 \mathrm{~m}$ (Thomas and Kuechle 1982). Consequently, even at the closest distances or altitudes tested, the noise levels gen- erated from the anthropogenic sources were less than those of the loudest natural vocalisations. This implies that the loudest noise levels generated by anthropogenic sources in this study would not be expected to cause physical damage to seals located beyond a few metres.

These data can be used to develop guidelines for distances and speeds of travel for vehicles near Weddell seal colonies. However, there are a number of other factors that will further influence the nature of the sound and therefore the corre- sponding effect on the seals, including variability in ice and snow conditions, water depths and underwater sound trans- mission characteristics. Direct comparisons between in-air and underwater noise levels and auditory thresholds are com- plicated by differences in acoustic impedance between air and water (Richardson et al. 1995). When comparisons are made, underwater hearing is found to be more sensitive than in-air hearing in pinnipeds, especially in phocids (Mohl

1968; Terhune 1991). However, it is unclear in which medium anthropogenic noise has the greater potential to affect the seals. In many cases, particularly in-air, the visual element of the stimulus confounds the response of a seal. In most studies, no distinction is made between the two compo- nents of a stimulus, so that a distance that is regarded as 'acoustically safe' may still result in an adverse behavioural response because of the visual aspects of the stimulus.

Direct comparisons between the effects of different types of anthropogenic noise are also difficult due to differences in engine type and vehicle structure, and frequency characteris- tics of the noise generated. For example, Hagglunds and quads differ in that the tracks of a Hagglunds do not isolate the engine noise from the ice as effectively as do the tyres of a quad. In addition, the contact between the tracks and the ice generates additional sound in a Hagglunds, while the rubber tyres of a quad do not. The result is that energy transfer into the ice is higher for the Hagglunds and therefore the decibel level under the ice is greater. The activity of the vehicle can also play an important role in determining the extent of noise effects. For instance, during flight, the noise from a heli- copter or Twin Otter aeroplane is first transmitted through the air before transmission through the ice into the water. Sound transmission through the ice and then into the water is complex and variable. Not only does sound attenuate as it travels along its path, but transmission loss also occurs at the air/ice interface, where most of the acoustic energy is reflected (Caruthers 1977). Therefore, although sound pres- sure is greater directly under the ice (Richardson et al. 1995), the noise level recorded under the ice is much less than in-air. During landing and idling, the skids of both the helicopter and the Twin Otter transmit sound directly through the ice into the water.

Higher vehicle speeds are also a factor influencing detec- tion thresholds and decibel levels when investigating noise effects. For many small vessels, an increase in speed results in higher noise levels (McCauley and Cato 2003). In the present study the increase in speed did not result in a signif- icant increase in decibel levels. Rather, only a small number of shifts occurred between the audibility categories, i.e. from inaudible at the slowest speed to barely audible at the fastest speed. Although speeds were not specified, previous research on cetaceans suggests that a slow-moving boat has less of an effect on behaviour than a fast-moving one (e.g. Richardson and Würsig 1997; National Research Council

2003). Again, determining precisely what an animal is responding to in these situations is difficult, because the acoustic and visual components of the stimuli are difficult to separate.

Table 4. Classification of Weddell seal calls

Based on Thomas and Kuechle (1982) and Pahl et al. (1997)

\begin{tabular}{lcl}
\hline Type & Symbol & Description \\
\hline Tone & O & Constant frequency, predominantly sinusoidal \\
Growl & L & Constant frequency, broad bandwidth, long call \\
Whoop & Constant frequency call with a terminal upsweep \\
Squeak & WA & Brief call with a constant frequency or rising frequency and an irregular waveform \\
Whistle ascending & Ascending frequency, sinusoidal waveform \\
Trill constant frequency & Narrow bandwidth trill with a constant frequency beginning, sinusoidal or frequency modulated \\
Trill & T & warroform to broad bandwidth, beginning with a frequency downsweep $(>2$ s) \\
Whistle descending & ND & Descending frequency, sinusoidal waveform $(<2$ s) \\
Mew & M & Abruptly descending frequency followed by a long constant frequency ending \\
Chug & C & Abruptly descending frequency followed by a brief constant frequency ending \\
Guttural glug (grunt) & G & Descending frequency call that is lower than a chug and has a brief duration \\
Whistle ascending grunt & WAG & Brief ascending whistle followed by a guttural glug, the two types alternate in a regular pattern \\
Knock & K & Abrupt, brief duration broadband sound \\
Tongue click & $\mathrm{CL}$ & Brief sharp call with slowly repeating elements, broadband and an irregular waveform \\
\hline
\end{tabular}


Received noise level will also vary according to abiotic conditions. Variations in the efficiency of coupling of sound energy into the ice, and thus into the water, imply that under- water received noise will vary depending on ice conditions. For example, a thick layer of snow will dampen the trans- mission of airborne sounds heard underwater. Although in this study we controlled for abiotic factors such as snow cover when generating sound profiles, Weddell seals under the ice would normally be exposed to varying noise levels because the ice surface on which over-snow vehicles travel and people walk is variable. It would be reasonable to assume that if the differences in received noise were in the order of a few decibels then the seals would be able to accommodate this by shifting their position in the water column, i.e. swim/call at a greater depth when the noise is louder. Wind speed will also affect the detectability of the vehicle, with increased wind speeds resulting in increased background noise levels, which in turn increase the detection threshold. In our study, variability of the underwater noise levels was recorded from the shallow and deep hydrophones (Table 3). Further study is necessary to determine the effect of such factors on Weddell seals.

The characteristic of the noise, in particular whether it is continuous or transient and constant or changing, is also an important factor influencing the effect of noise on wildlife. In rodents, exposure to continuous, intensive noise can result in health effects, while intermittent noise does not (Borg 1981), possibly because the animals recover between successive exposures (Bowles 1995). Humans have also been found to be more sensitive to continuous noise than to pulsed noise (at equivalent peak levels) (Fidell et al. 1970). In grey whales (Eschrichtius robustus) the threshold for distinct reactions to seismic pulses, with an average pulse

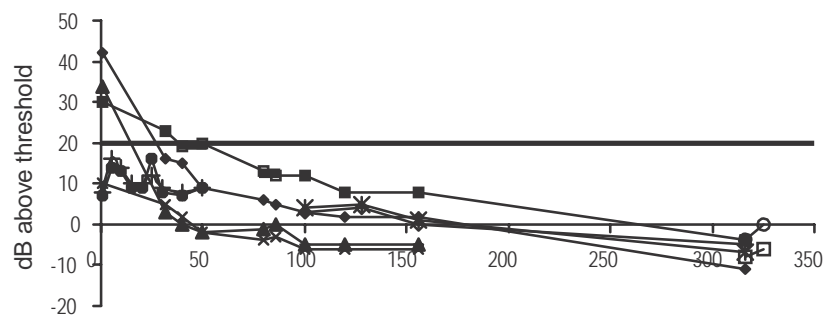

Distance from SRP $(\mathrm{m})$

$$
\begin{aligned}
& \longrightarrow \text { Hag slow shallow — Hag slow deep — Quad slow shallow — Quad slow deep } \\
& \longrightarrow \text { Hag fast shallow — Hag fast deep — Quad fast shallow — Quad fast deep } \\
& \text { — Ped shallow _ Ped deep }
\end{aligned}
$$

Fig. 5. Underwater noise levels generated by over-snow vehicles (where $\mathrm{Hag}=$ Hagglunds) and the pedestrian $(\mathrm{Ped})$ relative to the assumed detection threshold of the Weddell seal $(0 \mathrm{~dB})$. Noises below 0 are undetectable, noises between 0 and $20 \mathrm{~dB}$ are detectable by an actively listening seal in a quiet environment and noises above $20 \mathrm{~dB}$ (black line) are clearly detectable. The distance at which the noise first falls below the 20-dB threshold is an estimate based on the distances tested. Shallow and deep refer to the hydrophone depths (see text). level of $170 \mathrm{~dB}$ re. $1 \mu \mathrm{Pa}$ at $1 \mathrm{~m}$, was reported as $\sim 50 \mathrm{~dB}$ higher than that for continuous industrial noise (Richardson et al. 1995). Continuous noise can mask marine mammal vocalisations for long periods with a concomitant reduction in the effective range of communication (Bowles 1995). The distinction between transient and continuous sounds is not absolute, thereby making it diff icult to specify which noise types Weddell seals are more often exposed to. For example, much of the anthropogenic noise to which the seals are exposed in the Australian Antarctic Territory is vehicular, which varies in duration, is not impulsive, does not necessarily have an obvious start and end (transient), but does not originate from a fixed point (continuous).

Changing noises, e.g. those associated with rapid shifts in speed or direction of vehicle travel, have also been found to have a greater behavioural effect on wildlife than do constant noises. Rapid movements of vessels, with fast shifts in speed or direction, are especially disturbing to marine mammals (Richardson and Würsig 1997). Reactions of Californian sea lions (Zalophus californianus) to nearby boats were most common when motor noise levels varied (Richardson et al.

1995). Hauled-out sea lions were found to react most strongly if the craft made abrupt changes, which affected sounds levels. Myrberg (1990) reports that a sudden change in sound level is considered as a prime stimulus to avoid or to exhibit responses indicative of disturbance.

A number of factors determine whether anthropogenic noise is audible to Weddell seals. Thus, not only is it neces- sary to establish the noise levels generated by vehicles oper- ating at various distances, speeds and altitudes, it is also necessary to establish both the characteristics and the context of the noise. Because of the high variability of ice

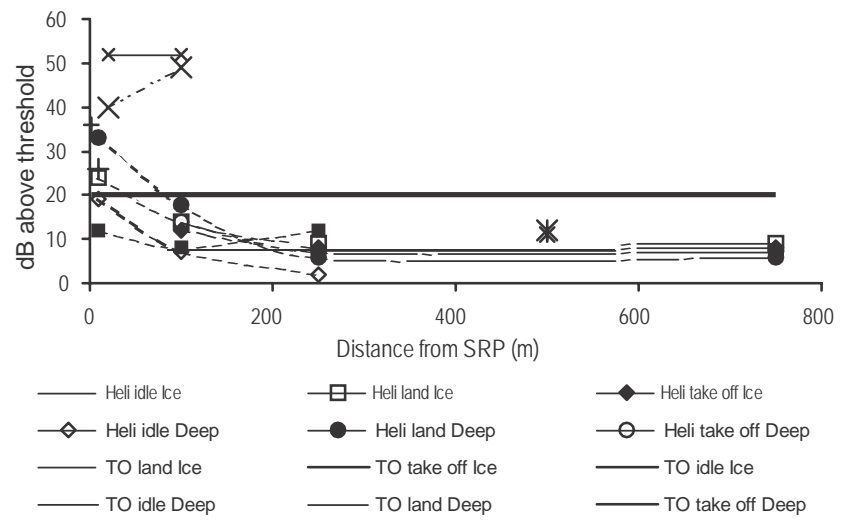

Fig. 6. Underwater noise levels generated by the aircraft (where TO $=$ Twin Otter) relative to the assumed detection threshold of the Weddell seal $(0$ $\mathrm{dB}$ ). Noises below 0 are undetectable, noises between 0 and $20 \mathrm{~dB}$ are detectable by an actively listening seal in a quiet environment and noises above $20 \mathrm{~dB}$ (black line) are clearly detectable. The distance at which the noise first falls below the 20-dB threshold is an estimate based on the distances tested. Shallow and deep refer to the hydrophone depths (see text). 


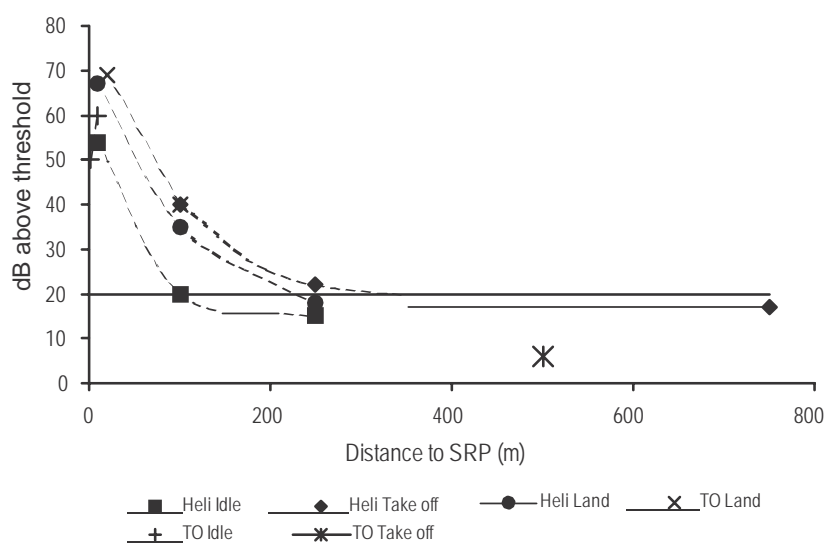

Fig. 7. In-air noise levels generated by aircraft (where TO $=$ Twin Otter) relative to the assumed detection threshold of the Weddell seal $(0 \mathrm{~dB})$. Noises below 0 are undetectable, noises between 0 and $20 \mathrm{~dB}$ are detectable by an actively listening seal in a quiet environment and noises above $20 \mathrm{~dB}$ (black line) are clearly detectable. The distance at which the noise first falls below the $20-\mathrm{dB}$ threshold is an estimate based on the distances tested.

and snow conditions, water depths, through-ice, and under- water sound transmission characteristics, our $f$ indings indi- cate general trends only. Furthermore, it is important to recognise that noise levels in-air are louder for humans than they are for seals. The lowest detection thresholds of a human are less than they are for seals (Terhune 2004). Therefore, noise levels that we consider loud and potentially disturbing to the Weddell seals may, in fact, be barely audible to the seals.

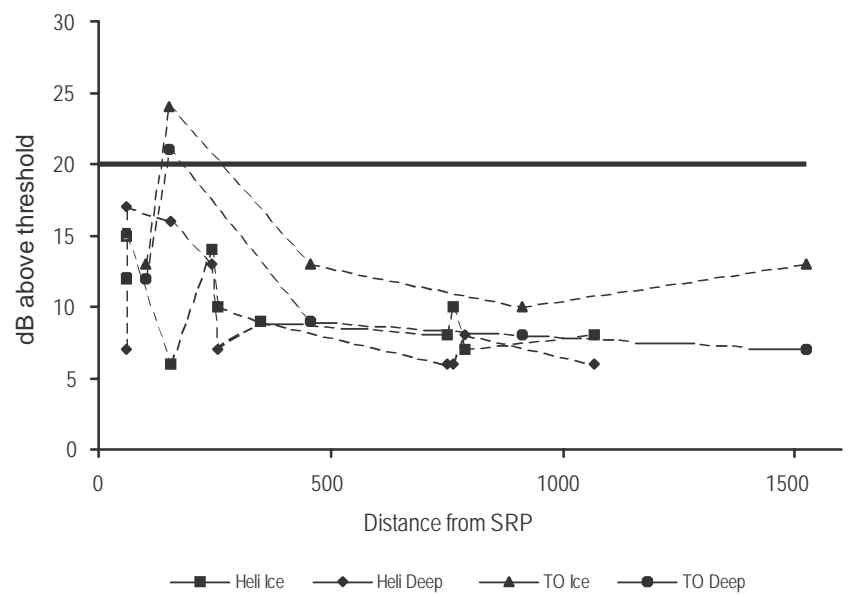

Fig. 8. Underwater noise levels generated by aircraft (where TO = Twin Otter) during flight relative to the assumed detection threshold of the Weddell seal $(0 \mathrm{~dB})$. Noises below 0 are undetectable, noises between 0 and 20 $\mathrm{dB}$ are detectable by an actively listening seal in a quiet environment and noises above $20 \mathrm{~dB}$ (black line) are clearly detectable. The distance at which the noise first falls below the 20-dB threshold is an estimate based on the distances tested. Shallow and deep refer to the hydrophone depths (see text).

\section{Vocal response experiment}

Our experiments to determine the effects of vehicle noise on Weddell seal vocal behaviour underwater indicated that during continuous vehicle noise at $0.075 \mathrm{kHz}$, Weddell seals detected the noise of a Hagglunds operating on the ice, and modified their behaviour as a result.

During this study, the location of the seals relative to the test stimulus was unknown. However, if vocal behaviour were only to change when noise levels were clearly audible $(>20 \mathrm{~dB}$ above threshold) then the seals would need to have been $\sim 31.6 \mathrm{~m}$ or closer to the SRP. Although this is possible,

it is more likely that the seals were closer to the pupping colony (300 $\mathrm{m}$ from the SRP), and therefore further away from our SRP. This is because males actively hold territories under the pupping colony during this time of the year (Siniff et al. 1977; Kooyman 1981). Even low levels of noise there- fore appear to have the potential to affect vocal behaviour in Weddell seals, particularly considering that male Weddell seals would likely be actively listening and communicating with other males and receptive females during this time (Thomas and Kuechle 1982).

Harp seals have been found to alter their vocal behaviour in a number of ways to compensate for increased noise in their environment. For example, they can adjust their call repertoire so that fewer call types are used that fall within or close to the frequency bandwidth of the noise (Serrano and Terhune 2002). Shifts in frequency have also been recorded for beluga whales (Delphinapterus leucas), when exposed to boat noise (Lesage et al. 1999). It has been suggested that this response was made to increase signal detection by avoid-

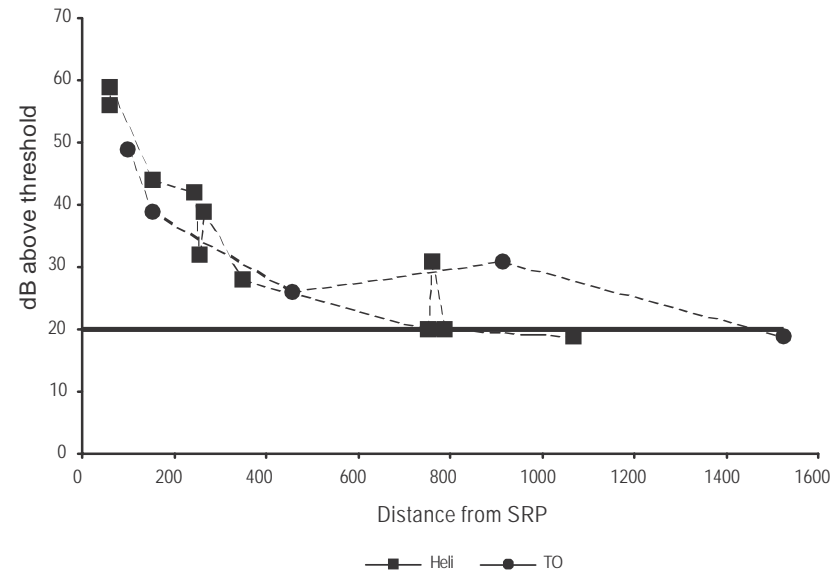

Fig. 9. In-air noise levels generated by aircraft (where TO = Twin Otter) during flight relative to the assumed detection threshold of the Weddell seal $(0 \mathrm{~dB})$. Noises below 0 are undetectable, noises between 0 and $20 \mathrm{~dB}$ are detectable by an actively listening seal in a quiet environment and noises above $20 \mathrm{~dB}$ (black line) are clearly detectable. The distance at which the noise first falls below the $20-\mathrm{dB}$ threshold is an estimate based on the distances tested. 
ing frequencies that were being masked (Lesage et al. 1999).

In our study, we did not record a decrease in call types within or close to the $0.075-\mathrm{kHz}$ frequency bandwidth, nor an increase in call types with frequencies $>0.075 \mathrm{kHz}$. The absence of a shift in frequency may be a result of the low noise levels to which the Weddell seals were exposed (e.g. the Hagglunds was simply not loud enough).

Another method observed among marine mammals of altering vocal behaviour to increase detection over noise is to decrease the use of low-amplitude calls and increase the use of high-amplitude calls. The use of long and repetitive call types, which 'cut through' background noise can also enhance detection (Watkins and Schevill 1979; Serrano and Terhune 2001). Weddell seals have been reported to lengthen many underwater vocalisations in response to conspecific vocalisations, with calls that were overlapped being longer in duration than solitary calls (Terhune et al. 1994). The increase in duration has been attributed to the addition of elements (for multielement calls). Detectability should increase for calls of longer duration in the presence of sporadic noise. Changes to vocalisations would either reduce or eliminate masking effects of the vehicle noise, thereby increasing detectability. However, we found no evidence of the length- ening of calls, for either the overlapped or non-overlapped call types in the presence of Hagglunds noise. The absence of an increase in call duration in response to Hagglunds noise probably reflected the fact that the noise level to which we exposed the animals was not sufficient to require the seals to alter individual vocalisations to enhance detection.

Although the amplitude of the noise generated by the Hagglunds in our study was low, and did not seem to cause any masking, the increase in ambient noise during vehicle

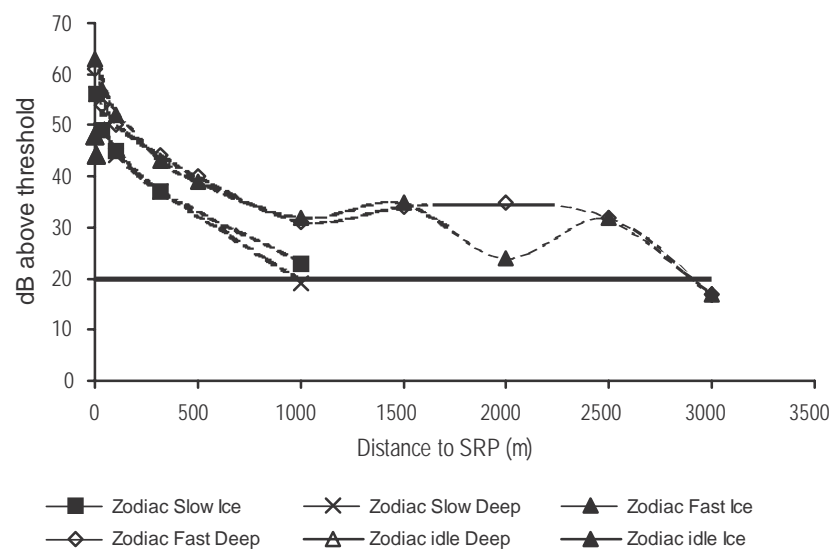

Fig. 10. Underwater noise levels generated by a travelling Zodiac relative to the assumed detection threshold of the Weddell seal $(0 \mathrm{~dB})$. Noises below 0 are undetectable, noises between 0 and $20 \mathrm{~dB}$ are detectable by an actively listening seal in a quiet environment and noises above $20 \mathrm{~dB}$ (black line) are clearly detectable. The distance at which the noise first falls below the 20-dB threshold is an estimate based on the distances tested. Shallow and deep refer to the hydrophone depths (see text). activity resulted in an increase in the time taken to record 100 definable calls and a decrease in the frequency of occurrence of calls. This suggests that either some seals left the immedi- ate area during vehicle noise, or that the seals vocalised less. Similar results have been found in a study on the influence of vessel noise on underwater vocal activity of harp seals (Terhune et al. 1979). The authors of this work found a sig- nificant reduction in the number of calls following a day of nearby vessel activity and suggested that this was due to either a decrease in the number of seals in the area, or a change in the vocalisations emitted. Studies on whales (e.g. right whales (Eubalaena glacialis) (Watkins 1986) and beluga whales (Blane and Jaakson 1994)) have also recorded

a decrease in calling rate during vessel approach/activity. Beluga whales, for example, have also been recorded to swim $80 \mathrm{~km}$ from their original location in response to a ship and remain away for 1-2 days (Richardson and Würsig

1997). Without knowledge of the activity of the seals, we are unable to determine which of the two theories best explains the response of Weddell seals in this study.

Continuous Hagglunds activity was found to have an effect on the vocal behaviour of the seals swimming under the ice. However, the effect was manifested only in the fre- quency of occurrence of calls and in the number of calls recorded in a specified period. We attribute the absence of changes to the individual calls, such as the lengthening of calls, to the low received noise levels of the Hagglunds. Experiments in which the location of the seals are known would greatly improve our knowledge of the distance at which the noise generated by a Hagglunds would affect the actual calls of Weddell seals underwater and the received noise levels at which these changes would occur.

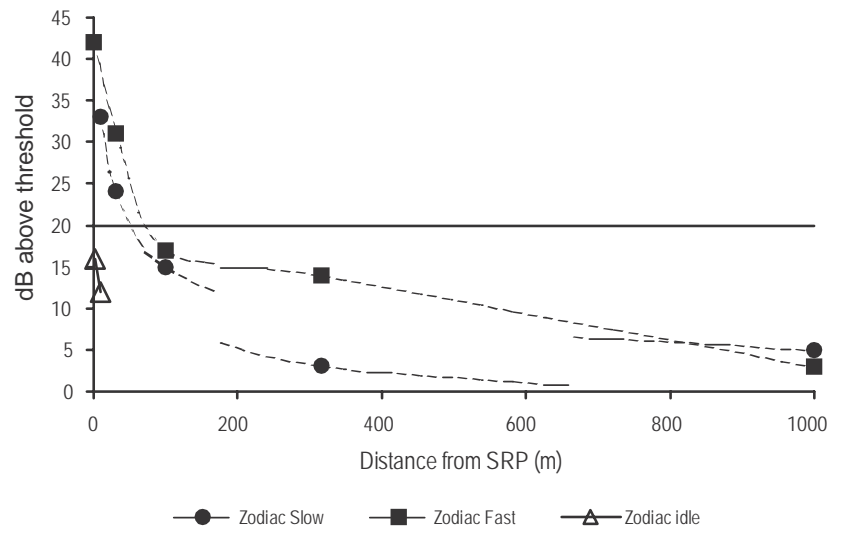

Fig. 11. In-air noise levels generated by a travelling Zodiac relative to the assumed detection threshold of the Weddell seal $(0 \mathrm{~dB})$. Noises below 0 are undetectable, noises between 0 and $20 \mathrm{~dB}$ are detectable by an actively listening seal in a quiet environment and noises above

$20 \mathrm{~dB}$ (black line) are clearly detectable. The distance at which the noise $f$ irst falls below the $20-\mathrm{dB}$ threshold is an estimate based on the distances tested. 


\section{Acknowledgments}

We thank Sarah Brown, Kate Bodley and Marjolein van Polanen Petel and other members of the 54th and 55th ANARE expeditions to Casey Station and Davis Station. We also thank the Australian Antarctic Division for providing the geographic data for the maps used (Fig. 1). The study was conducted with permission from the Australian Antarctic Animal Ethics Committee, Australian Antarctic Division and the Animal Ethics Committee of the University of Tasmania. The Australian Antarctic Division, Sea World Research and Rescue Foundation, Natural Sciences and Engineering Research Council (NSERC) of Canada and the University of Tasmania supported fieldwork and data anal-ysis. Additional funding was given to TDvPP from the Australian Government through an Australian Postgraduate Award and from the Sustainable Tourism Cooperative Research Centre.

\section{References}

AAD (2004a). 'Australian Antarctic Division Field Manual 2004/05.' (Australian Antarctic Division: Kingston, Tasmania)

AAD (2004b). Australian Antarctic Division website http://www.aad. gov.au/default.asp?casid $=3805$

Blane, J. M., and Jaakson, R. (1994). The impact of ecotourism boats on the St Lawrence beluga whales. Environmental Conservation 21, 267-269.

Borg, E. (1981). Physiological and pathogenic effects of sound. Acta Oto-Laryngologica 381(Suppl.), 7-68.

Born, E. W., Riget, F. F., Dietz, R., and Andriashek, D. (1999). Escape responses of hauled out ringed seals (Phoca hispida) to aircraft disturbance. Polar Biology 21, 171-178. doi:10.1007/s003000050349

Bowles, A. E. (1995). Responses of wildlife to noise. In 'Wildlife and Recreationists Coexistence Through Management and Research'. (Eds R. L. Knight and K. J. Gutzwiller.) pp. 109-156. (Island Press: Washington, DC.)

Burton, H. R., and van den Hoff, J. (2002). Humans and the southern elephant seal Mirounga leonina. Australian Mammalogy 24, 127-139.

Caruthers, W. W. (1977). 'Fundamentals of Marine Acoustics.' (Elsevier: New York.)

Cooper, J., Avenant, N. L., and Lafite, P. W. (1994). Airdrops and king penguins: a potential conservation problem at sub-antarctic Marion Island. Polar Record 30, 277-282.

Culik, B., Adelung, D., and Woakes, A. J. (1990). The effects of distur- bance on the heart rate and behaviour of Adélie penguins (Pygoscelis adeliae) during the breeding season. In 'Antarctica Ecosystems. Ecological Change and Conservation'. (Eds K. R. Kerry and G. Hempel.) pp. 177-182. (Springer-Verlag: Berlin.)

Evans, W. E., Thomas, J. A., and Davis, R. W. (2004). Vocalisations from Weddell seals (Leptonychotes weddellii) during diving and for- aging. In 'Echolocation in Bats and Dolphins'. (Eds J. A. Thomas, C. F. Moss and M. Vater.) pp. 541-547. (University of Chicago Press: Chicago, IL.)

Fidell, S., Pearsons, K., Grignetti, M., and Green, D. (1970). The nois- iness of impulsive sounds. Journal of the Acoustical Society of America 48, 1304-1310. doi:10.1121/1.1912277

Foote, A. D., Osborne, R. W., and Hoelzel, A. R. (2004). Whale-call response to masking boat noise. Nature 428,910 .
Giese, M., and Riddle, M. (1999). Disturbance of emperor penguin Aptenodytes forsteri chicks by helicopters. Polar Biology 22, 366-371.

Green, K., and Burton, H. R. (1988). Annual and diurnal variations in the underwater vocalizations of Weddell seals. Polar Biology $\mathbf{8}$, 161-164. doi:10.1007/BF00443447

Henry, E., and Hammill, M. O. (2001). Impact of small boats on the haulout activity of harbour seals (Phoca vitulina) in Metis Bay, Saint Lawrence Estuary, Quebec, Canada. Aquatic Mammals 27, 140-148.

Hirsch ,I. J. (1952). 'The Measurement of Hearing.' (McGraw-Hill Inc.: Toronto.) IAATO (2004). International Association of Antarctic Tour Operators home page http://www.iaato.org/wildlife.html

Kastak, D., and Schusterman, R. J. (1998). Low-frequency amphibious hearing in pinnipeds: methods measurements, noise, and ecology. Journal of the Acoustical Society of America 103, 2216-2228. doi:10.1121/1.421367

Kimball, L. A. (1999). The Antarctic Treaty systems. In 'Conservation and Management of Marine Mammals'. (Eds J. R. Twiss Jr and R. Reeves.) pp. 199-223. (Melbourne University Press: Melbourne.)

Kooyman, G. L. (1981). Weddell seal Leptonychotes weddelli. In 'Handbook of Marine Mammals'. (Eds S. H. Ridgway and R. J.Harrison.) (Academic Press: London.)

Lesage, V., Barrette, C., Kingsley, M. C. S., and Sjare, B. (1999). The effect of vessel noise on the vocal behaviour of belugas in the St Lawrence River estuary, Canada. Marine Mammal Science 15, 65-84.

McCauley, R. D., and Cato, D. H. (2003). Acoustics and marine mammals: introduction, importance, threats and potential as a research tool. In 'Marine Mammals, Fisheries, Tourism \& Management Issues'. (Eds N. Gales, M. Hindell and R. Kirkwood.) pp. 344-365. (CSIRO: Melbourne.)

Mohl, B. (1968). Auditory sensitivity of the common seal in air and water. Journal of Auditory Research 8, 27-38.

Morton, A. B., and Symonds, H. K. (2002). Displacement of Orcinus orca (L.) by high amplitude sound in British Columbia, Canada. ICES Journal of Marine Science 59, 71-80. doi:10.1006/jmsc.2001.1136

Myrberg, A. A. J. (1990). The effects of man-made noise on the behav- ior of marine animals. Environment International 16, 575-586. doi:10.1016/0160-4120(90)90028-5

National Research Council (2003). 'Ocean Noise and Marine Mammals.' (The National Academies Press: Washington, DC.)

Pahl, B. C., Terhune, J. M., and Burton, H. R. (1997). Repertoire and geographic variation in underwater vocalisations of Weddell seals (Leptonychotes weddellii, Pinnipedia: Phocidae) at the Vestfold Hills, Antarctica. Australian Journal of Zoology 45, 171-187. doi:10.1071/ZO95044

Ray, C., and deCamp, M. A. (1969). Watching seals at Turtle Rock. Natural History 78, 26-35.

Richardson, W. J., and Würsig, B. (1997). Influences of made-made noise and other human actions on cetacean behaviour. Marine and Freshwater Behavioural Physiology 29, 183-209.

Richardson, W. J., Greene, C. R. J., Malme, C., and Thomson, D. H. (1995). 'Marine Mammals and Noise.'(Academic Press: San Diego, CA.)

Scarpaci, C., Bigger, S. W., Corkeron, P. J., and Nugegoda, D. (2000). Bottlenose dolphins (Tursiops truncatus) increase whistling in the presence of 'swim-with-dolphin' tour operations. Journal of Cetacean Research and Management 2, 183-185.

Schevill, W. E., and Watkins, W. A. (1971). Directionality of the sound beam in Leptonychotes weddelli (Mammalia: Pinnipedia). In 'Antarctic Research Series'. (Ed. W. H Burt.) pp. 163-168. (American Geophysical Union: Washington, DC.) 
Serrano, A., and Terhune, J. M. (2001). Within-call repetition may be an anti-masking strategy in underwater calls of harp seals (Pagophilus groenlandicus). Canadian Journal of Zoology 79, 1410-1413. doi:10.1139/cjz-79-8-1410

Serrano, A., and Terhune, J. M. (2002). Antimasking aspects of harp seal (Pagophilus groenlandicus) underwater vocalisations. Journal of the Acoustical Society of America 112, 3083-3090. doi:10.1121/ 1.1518987

Siniff, D. B., DeMaster, D. P., Hofman, J. R., and Eberhardt, L. L. (1977). An analysis of the dynamics of a Weddell seal population. Ecological Monographs 47, 319-335.

Terhune, J. M. (1988). Detection thresholds of a harbor seal to repeated underwater high-frequency, short-duration, sinusoidal pulses. Canadian Journal of Zoology 66, 1578-1582.

Terhune, J. M. (1991). Masked and unmasked pure tone detection thresholds of a harbor seal listening in air. Canadian Journal of Zoology 69, 2059-2066.

Terhune, J. M. (2004). Through-ice communication by Weddell seals may not be practicable. Polar Biology 27, 810-812. doi:10.1007/ s00300004-0659-4

Terhune, J. M., and Ronald, K. (1971). The harp seal, Pagophilus groenlandicus (Erxleben, 1777). X. The air audiogram. Canadian Journal of Zoology 49, 385-390.

Terhune, J. M., and Ronald, K. (1972). The harp seal, Pagophilus groenlandicus (Erxleben, 1777). III. The underwater audiogram. Canadian Journal of Zoology 50, 565-569.

Terhune, J. M., and Ronald, K. (1975). Underwater hearing sensitivity of two ringed seals (Phoca hispida). Canadian Journal of Zoology $53,227-231$.

Terhune, J. M., and Turnbul,I S. (1995). Variation in the psychometric functions and hearing thresholds of a harbour seal. In 'Sensory Systems of Aquatic Mammals'. (Eds R. A. Kastelein, J. A. Thomas and P. E. Nachtigall.) pp. 81-93. (De Spil Publishers: Woerden, The Netherlands.)
Terhune, J. M., Stewart, R. E. A., and Ronald, K. (1979). Influence of vessel noises on underwater vocal activity of harp seals. Canadian Journal of Zoology 57, 1337-1338.

Terhune, J. M., Grandmaitre, N. C., Burton, H. R., and Green, K. (1994). Weddell seals lengthen many underwater calls in response to conspecific vocalizations. Bioacoustics 5, 223-226.

Thomas, J. A., and Kuechle, V. B. (1982). Quantitative analysis of Weddell seal (Leptonychotes weddelli) underwater vocalizations at McMurdo Sound, Antarctica. Journal of the Acoustical Society of America $\mathbf{7 2}$ 1730-1738. doi:10.1121/1.388667

van Parijs, S. M., and Corkeron, P. J. (2001). Boat traffic affects the acoustic behavior of Pacific humpback dolphins, Sousa chinensis. Journal of the Marine Biological Association 81, 533-538.

Watkins, W. A. (1986). Whales reactions to human activities in Cape Cod waters. Marine Mammal Science 2, 251-262.

Watkins, W. A., and Schevill, W. E. (1979). Distinctive characteristics of underwater calls of the harp seal, Phoca groenlandica, during the breeding season. Journal of the Acoustical Society of America 66, 983-988. doi:10.1121/1.383375

Wilson, R. P., Culik, B., Danfeld, R., and Adelung, D. (1991). People in Antarctica - how much do Adélie penguins Pygoscelis adeliae care? Polar Biology 11, 363-370. doi:10.1007/BF00239688

Wolski, L. F., Anderson, R. C., Bowles, A. E., and Yochem, P. K. (2003). Measuring hearing in the harbor seal (Phoca vitulina): comparison of behavioural and auditory brainstem response techniques. Journal of the Acoustical Society of America 113, 629-637. doi:10.1121/ 1.1527961 